\title{
The Lefkada, Ionian Sea (Greece), shock ( $M w$ 6.2) of 14 August 2003: Evidence for the characteristic earthquake from seismicity and ground failures
}

\author{
Gerassimos A. Papadopoulos ${ }^{1}$, Vassilios K. Karastathis ${ }^{1}$, Athanassios Ganas ${ }^{1}$, Spyros Pavlides ${ }^{2}$, \\ Anna Fokaefs ${ }^{1}$, and Katerina Orfanogiannaki ${ }^{1}$ \\ ${ }^{1}$ Institute of Geodynamics, National Observatory of Athens, 11810 Athens, Greece \\ ${ }^{2}$ Department of Geology, Aristotelian University of Thessaloniki, 54006 Thessaloniki, Greece
}

(Received October 17, 2003; Revised December 9, 2003; Accepted December 10, 2003)

\begin{abstract}
The earthquake ( $M w$ 6.2, Ms 6.4) of 14 August 2003 which occurred in the Lefkada segment of the Cephalonia Transform Fault, Ionian Sea (Greece), was associated with dextral strike-slip faulting striking NNE-SSW. Reevaluation of instrumental and documentary sources show that the 1914, 1948 and 2003 earthquakes ruptured the same fault segment and that all had similar size, which implies that this segment produces characteristic earthquakes. This is verified by the magnitude-frequency diagram which for the instrumental period of 1911-2003 exhibits a relatively narrow range of magnitudes near the maximum $(\sim \mathrm{Ms} 6.4)$, deviation from the log linear relationship and a gap in the moderate-magnitude range. Field observations indicate that the 2003 earthquake and past strong shocks caused on Lefkada island impressively similar ground failures at exactly the same sites: extensive landslides and soil liquefaction, which signifies comparable strong motion features as an additional evidence of the characteristic earthquake. However, while the maximum seismic intensity for the 1914 and 1948 strong shocks is estimated as Imax $=$ IX $-\mathrm{X}$ (MM scale), the impact of the 2003 shock was less severe (Imax = VIII) possibly due to building strengthening after 1948.

Key words: Ionian Sea, Lefkada island, strike-slip faulting, earthquake size, characteristic earthquake, landslide, soil liquefaction, yield acceleration.
\end{abstract}

\section{Introduction}

On 14 August 2003 a strong earthquake ruptured the central Ionian Sea, Greece, causing remarkable damage and ground failures on the Lefkada island. The earthquake source, located offshore in the Lefkada Fault Segment (LFS) of the dextral Cephalonia Transform Fault (e.g. Louvari et al., 1999), is well-known from past strong earthquakes (Fig. 1, Table 1). We have evidence that the 14.08.2003 shock was similar with past Lefkada shocks. To support this we compare the size, location, ground failures and other macroseismic effects of the 2003 earthquake with those of three previous instrumental earthquakes and conclude that the Lefkada fault segment generates characteristic earthquakes. We suggest that those events cause similar strong ground motion and ground failures on the same spots of observations under the same ground conditions.

\section{The 2003 Mainshock and Its Aftershocks}

According to the National Observatory of Athens, Institute of Geodynamics (NOAGI), the 14.08.2003 (05:14:53.9 GMT) earthquake had the next focal parameters: epicenter at $38.81^{\circ} \mathrm{N}, 20.56^{\circ} \mathrm{E}$ (Fig. 1), focal depth $h=12 \mathrm{~km}$, magnitude $M_{L}=5.9, M s=6.4$. Moment magnitude $M w=6.2$ was calculated teleseismically by other institutes like USGS (http:// gldss7.cr.usgs.gov/neis/bulletin/bulletin.html) and Harvard

Copy right(c) The Society of Geomagnetism and Earth, Planetary and Space Science (SGEPSS); The Seismological Society of Japan; The Volcanological Society of Japan; The Geodetic Society of Japan; The Japanese Society for Planetary Sciences. (http:// www.seismology.harvard.edu/CMTsearch.html).

Up to 22 September 2003 more than 270 aftershocks of $M_{L} \geq 2.9$ (or $M_{S} \geq 3.4$ ) were recorded. The strongest of them $(M s=5.2)$ occurred on 14.08.2003 at 16:18:03.9 GMT. The parameter $b$ of the frequency-magnitude or G$\mathrm{R}$ relationship and the aftershock decay exponent, $k$, of the Omori law were found by the least-square approximation to have typical values for Greek earthquakes: $b=1.10$, $k=1.24$.

The aftershock epicenters are distributed in two clusters (Fig. 1). The north cluster has a length $L \approx 35 \mathrm{~km}$ which is consistent with the aftershock area length predicted by empirical $M / L$ formulas. In fact, for $M s=6.4$ and $M w=6.2$ we get $L=38 \mathrm{~km}$ and $L=32 \mathrm{~km}$, respectively, from formulas found for Mediterranean Sea earthquakes by $\mathrm{Pa}-$ padopoulos et al. (2003). For $M w=6.2$ and strike-slip faulting, the worldwide formula of Wells and Coppersmith (1994) yields $L=19 \mathrm{~km}$. The length of the south aftershocks cluster is $L \sim 25 \mathrm{~km}$. The area of $L \sim 15-20 \mathrm{~km}$ between the two clusters is almost free of epicenters. A plausible explanation of the entire aftershock picture is that this area is an asperity or a barrier which remained unruptured from the 2003 mainshock and that the south cluster represents rather a triggered seismicity, due to stress increase from the mainshock, than typical aftershock activity. This is supported also by that in this region the activity of $M s \geq 3.2$ started about twelve hours after the main shock.

Fault plane solutions determined teleseismically indicated the next nodal planes: NP1 (strike/dip/slip): 104\% $82 \%$ 


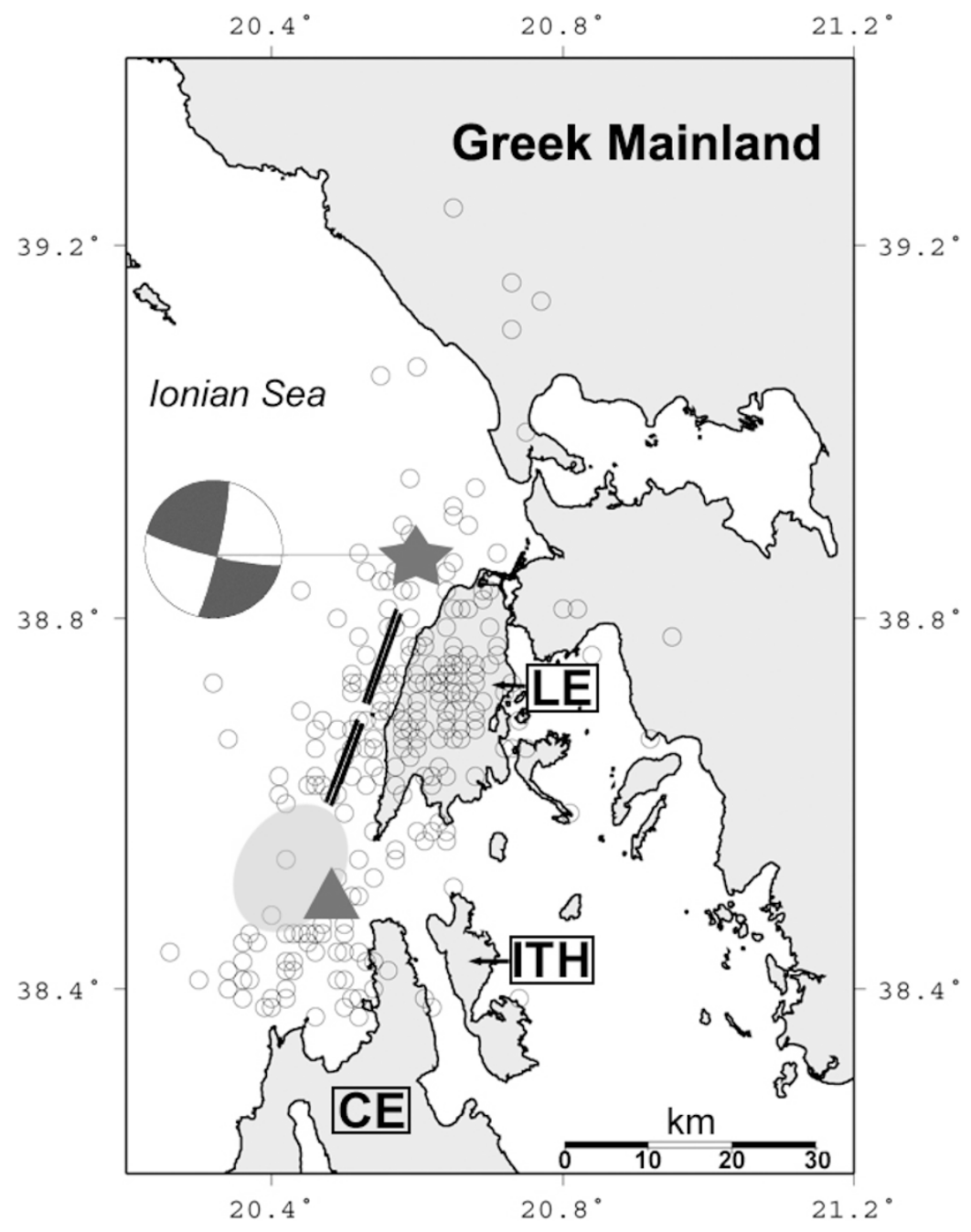

Fig. 1. Aftershock epicenters (circles) of the 14 August 2003 main shock (solid star) in the Lefkada fault segment (double dashed line). The north and south aftershock clouds are separated by a free of epicenters region (ellipse). Triangle shows the epicenter of the 22 April 1948 earthquake (Ms 6.5). Epicenters of the 27 November 1914 (Ms 6.3) and 30 June 1948 (Ms 6.4) earthquakes are nearly identical with the 2003 main shock epicenter. Key for geography: $L E=$ Lefkada Isl., $C E=$ Cephalonia Isl., $I T H=$ Ithaki Isl.

$6^{\circ}$ (USGS), $17^{\circ} / 60^{\circ} /-175^{\circ}$ (Harvard); NP2 (strike/dip/slip): $13 \% 84^{\circ} \% 172^{\circ}$ (USGS), $285^{\circ} / 86^{\circ} \%-30^{\circ}$ (Harvard). The NNE-SSW elongation of the aftershock area implies that the nodal plane 2 of the USGS solution and the nodal plane 1 of the Harvard solution represent the fault plane. Then, it results that the motion in the seismic fault was dextral strikeslip with a small dip-slip component.

\section{Seismicity Evidence for the Characteristic Earthquake Model}

The characteristic earthquake model was developed during the beginning of 80's from geological data regarding Quaternary faulting in California and Japan (e.g. Schwartz et al., 1981; Wesnousky et al., 1983; Schwartz and Coppersmith, 1984). The model predicts that faults or fault segments tend to generate essentially same size earthquakes having a relatively narrow range of magnitudes near the maximum and has some important implications: (1) on individual faults and fault segments the earthquake occurrence does not follow a log linear G-R relationship that is dominated by the characteristic event, (b) G-R has a low $b$ value in the moderate-magnitude range, (c) estimates of the likelihood of large earthquake occurrence based on extrapolation of the frequency of occurrence of small earthquakes may be subject to considerable error. According to this model ruptures are limited to persistent segments, displacement per event at a point is constant, while slip rate along strike is variable. The model makes no assumptions about recurrence. Observations in favour of the characteristic earthquake model were made also in the Aleutian arc, the Mexican subduction zone, the Mount St. Helens and the Xianshuihe fault in China. However, earthquake statistics (e.g. Kagan, 1993) and observations about the fault behavior (e.g. Thatcher, 1990; Grant, 1996; Roberts, 1996) indicated patterns of rather uncharacteristic earthquakes.

G-R relationships for segments of the Hellenic Arc-Trench system showed that deviations from linearity could be explained by the characteristic earthquake model with the Ionian Islands segment being a possible exception (Papadopoulos et al., 1993). However, this exception may be only apparent due to that the examination was made for the ensemble of earthquakes sampled without regard to specific fault segments. To resolve this we examined the magnitude frequency statistics for a sample of LFS earthquakes (Fig. 2). 
Table 1. Focal parameters and macroseismic observations of the instrumental Lefkada strong shocks. Key for parameters: Lat=latitude, Long=longitude, $M s=$ surface-wave magnitude, Imax =maximum seismic intensity in MM scale. Key for references: (1) Papazachos and Papazachou (1997); (2) Eginitis (1916); (3) Critikos (1916); (4) Valle (1951); (5) Galanopoulos (1950); (6) NOAGI; (ar) Anonymous report of NOAGI Book of Earthquakes 1892-1915; (p) Present paper; (pr) Press reports; (sr) Seismological reports sent to NOAGI by local observers. Key for date, time and geography: $\mathrm{d}=$ day, $\mathrm{m}=\mathrm{month}$, $\mathrm{y}=$ year, $\mathrm{h}=$ hour, $\min =$ minute, $\mathrm{s}=$ second, $\mathrm{n}=$ north, $\mathrm{w}=$ west, $\mathrm{s}=$ south, $\mathrm{c}=$ central, $\mathrm{L}=$ Lefkada island.

\begin{tabular}{|c|c|c|c|c|c|}
\hline $\begin{array}{l}\text { Date }(y \text { m d }) \\
\text { Time }(G M T) \\
h \text { min } s\end{array}$ & Lat $\left(N^{0}\right)$ & $\operatorname{Long}\left(E^{0}\right)$ & $M s$ & $\begin{array}{l}\text { Imax } \\
\text { Location }\end{array}$ & Ground failures \\
\hline $\begin{array}{l}19141127 \\
14: 39: 46\end{array}$ & $38.80(\mathrm{p})$ & $20.60(p)$ & $6.3(1)$ & $\begin{array}{l}\text { X-XI } \\
\text { Tsoukalades (nL) (p) }\end{array}$ & $\begin{array}{l}\text { Landslides of length } \sim 3 \mathrm{~km} \text {, } \\
\text { Pefkoulia-Agios Nikitas coastal } \\
\text { zone (nwL). In the sandy beach } \\
\text { of Agios Nikitas a ground crater } \\
\text { was opened. Landslides and } \\
\text { rock falls also in other places } \\
\text { of wL }(\text { ar, } 2,3) \text {. }\end{array}$ \\
\hline $\begin{array}{l}19480422 \\
10: 42: 45\end{array}$ & $38.49(4)$ & $20.48(4)$ & $6.5(1)$ & $\begin{array}{l}\text { IX } \\
\text { Vassiliki (sL) } \\
\text { Kalamitsi (cwL) (p) }\end{array}$ & $\begin{array}{l}\text { Landslides and rockfalls in } \\
\text { cwL (sr, pr, 5). }\end{array}$ \\
\hline $\begin{array}{l}19480630 \\
12: 21: 13\end{array}$ & $38.78(\mathrm{p})$ & $20.60(\mathrm{p})$ & $6.4(1)$ & $\begin{array}{l}\text { X } \\
\text { Lefkada city (nL) (p) }\end{array}$ & $\begin{array}{l}\text { Landslides in Pefkoulia (nwL). } \\
\text { In the beach of Agios Nikitas (nwL) } \\
\text { a ground crater of diameter } \sim 3 \mathrm{~m} \\
\text { and depth } \sim 1 \mathrm{~m} \text { was observed (sr, } \\
\mathrm{pr}, 5 \text { ) }\end{array}$ \\
\hline $\begin{array}{c}20030814 \\
05: 14: 54\end{array}$ & $38.81(6)$ & $20.56(6)$ & $6.4(6)$ & $\begin{array}{l}\text { VIII+ } \\
\text { Lefkada city (nL) (p) }\end{array}$ & see text \\
\hline
\end{tabular}

It is clear the deviation from the log linear relationship that is dominated by the characteristic event in the magnitude range from 6.3 to 6.5 , and that the G-R relationship has a low $b$ value in the moderate-magnitude range.

Since such results are sensitive in earthquake magnitude we evaluate critically the size and locations of the three strong, instrumental Lefkada shocks that occurred before 2003 and dominate the upper magnitude bound in G-R. Magnitudes of Greek earthquakes occurring from 1911 to 1971 were determined (Papazachos and Comninakis, 1971) from the average ground amplitude, $A$ (in microns), as inferred from the maximum recorded amplitude at the two horizontal components N-S and E-W of Mainka (instrument pe$\left.\operatorname{riod} T_{o}=5.5-6.5 \mathrm{~s}\right)$ and/or Wiechert $\left(T_{o}=9.0-9.5 \mathrm{~s}\right)$ seismographs from the formula $M=\log A+1.42 \log \Delta+0.20$, where $\Delta$ (in $\mathrm{km}$ ) is the epicentral distance. Magnitudes determined from amplitudes recorded by such intermediate period seismographs have error less than 0.3 and are equivalent to surface-wave magnitude for $M s \geq 6.0$ (see for a review in Papazachos and Papazachou, 1997) and, therefore, are directly comparable with magnitudes of more recent events. For the verification of epicenters and magnitudes we remeasured S-P arrival times and wave amplitudes on the original records of Mainka and/or Wiechert instruments for the 1914 and 1948 strong earthquakes. In addition, reevaluation of seismic intensity was made from seismological reports archived in NOAGI, press reports and scientific publications. The three shocks are analysed as follows (for additional data sources see Table 1):

27 November 1914: From the arrival times of the $P$ $(14: 40: 23)$ and $S(14: 40: 56)$ phases and the wave polarity in the ATH Mainka seismograph we located the epicenter at distance $\Delta=298 \mathrm{~km} \mathrm{NW}$ from ATH, at $38.80^{\circ} \mathrm{N}$, $20.60^{\circ} \mathrm{E}$ in the north section of the Lefkada fault segment, which is very close to locations adopted in several earthquake catalogues. The $P$-wave crustal velocity assumed

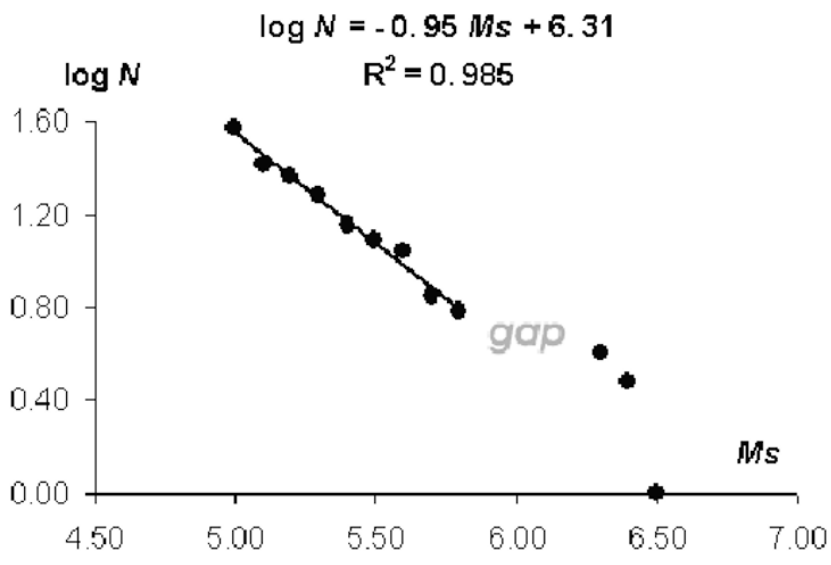

Fig. 2. Magnitude-frequency relationship for earthquakes occurring in the Lefkada falut segment from 1911 to 14 August 2003; $N$ is the cumulative number of aftershocks of surface-wave magnitude $\geq 5.0$. Regression line fits well only the magnitude range from 5.0 to 5.8 A gap in moderate magnitudes is obvious.

equals $6.6 \mathrm{~km} / \mathrm{s}$. This epicental location is consistent with Imax $=\mathrm{X}$ in Rossi-Forel scale (Critikos, 1916), or X-XI in MM (modified Mercalli) scale according to our estimation, which was observed in north Lefkada. The magnitude was verified to be $M s=6.3$.

22 April 1948: $M s=6.5$ (for calculation method see above). From $S$ - $P$ time differences ranging from $33.2 \mathrm{~s}$ to $184.0 \mathrm{~s}$, measured in thirteen stations at epicentral distances up to $16.4^{\circ}$, Valle (1951) determined epicentral location at $38.49^{\circ} \mathrm{N}, 20.48^{\circ} \mathrm{E}$ at $\Delta=280 \mathrm{~km}$ from ATH. Therefore, we suggest that this event ruptured the south Lefkada fault segment which resisted the 2003 rupture. This epicentral location is consistent with $\operatorname{Imax}=\mathrm{IX}-\mathrm{X}$ in Mercalli scale (Galanopoulos, 1950), or IX (MM) according to our estimation, reported from SW Lefkada and north Ithaki island (Fig. 1). 


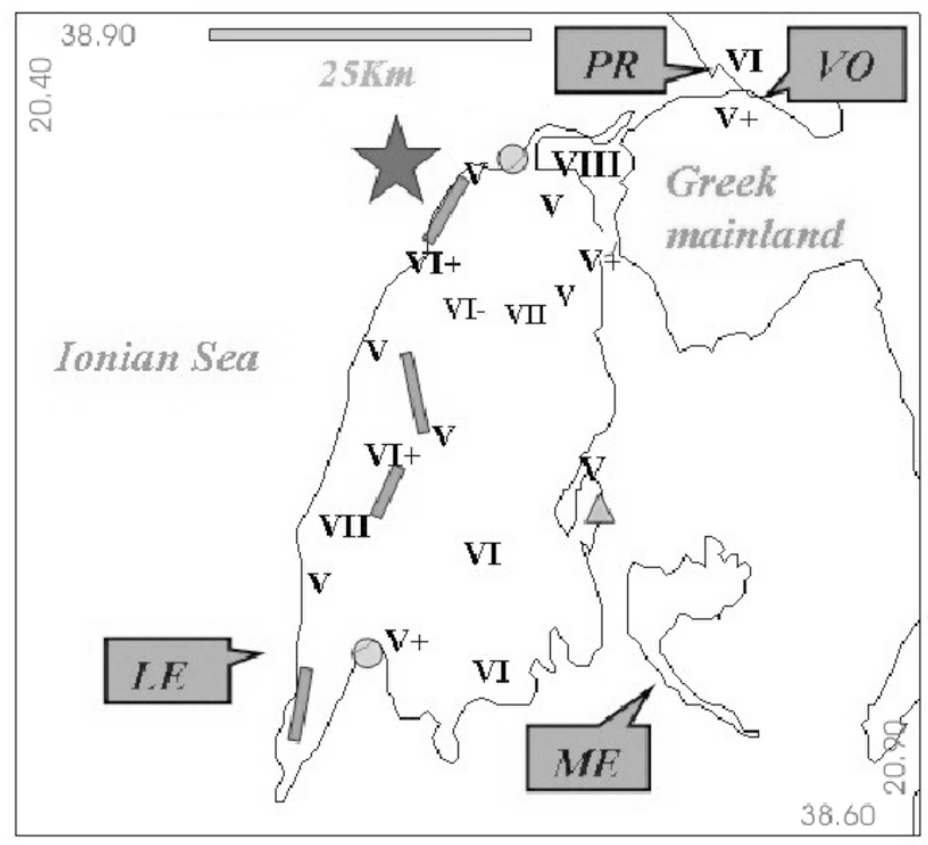

Fig. 3. Macroseismic field of the 14 August 2003 main shock (solid star). Maximum intensity of VIII degree in MM and EMS scales was observed in the Lefkada city. In the remaining part of Lefkada island intensities ranged between V and VII as follows : VII (Lazarata, Dragano), VI+ (Agios Nikitas, Komilio), VI (Syvros, Maradochori), VI- (Asprogerakata), V+ (Lygia, Vasiliki), V (Tsoukalades, Apolpena, Spanochori, Kalamitsi, Chortata, Nydri, Athani). Symbol key: solid circle = soil liquefaction and failure in port facilities in Marina district, Lygia and Vassiliki; solid triangle = soil liquefaction in Nydri; solid bar = landslides, rock falls and associated ground fissures in Tsoukalades-Pefkoulia-Agios Nikitas, Kalamitsi-Chortata, Komilio-Dragano, Athani-Egremni (all sequences of intensity, port failures and ground failures are from north to south). Key for geography: $L E=$ Lefkada Isl., $M E=$ Meganisi Isl., $P R=$ Preveza, $V O=$ Vonitsa. Information about soil liquefaction in Nydri and Vassiliki was taken from Pavlides et al. (2003).

30 June 1948: $M s=6.4$ (for calculation method see above). From $20 S$ - $P$ time differences ranging from $35 \mathrm{~s}$ to $178 \mathrm{~s}$ measured at distances up to $15.6^{\circ}$, we determined an epicentral location at $38.78^{\circ} \mathrm{N}, 20.60^{\circ} \mathrm{E}$, that is in the north part of the Lefkada fault ( $\Delta=295 \mathrm{~km}$ from ATH). Imax $=\mathrm{X}-\mathrm{XI}$ in Mercalli scale (Galanopoulos, 1950), or X (MM) according to our estimation, was reported from north Lefkada, which is consistent with the epicentral location.

The above indicate that the 27.11.1914, 30.06.1948 and 14.08.2003 shocks had nearly identical epicentral locations at the north Lefkada fault segment while the 22 April 1948 shock ruptured the south part of this segment.

\section{Field Evidence for the Characteristic Earth- quake Model}

A post-event field survey revealed that the 14.08.2003 shock caused structural damage in several towns and villages as well as extensive landslides, rock falls, soil liquefaction and ground cracks in many locations of Lefkada island. A more detailed description of the earthquake effects will be presented elsewhere. Here we report only on the main observations with the purpose to compare the pattern of the 2003 macroseismic field with the 1914 and 1948 macroseismic field patterns.

As regards the 14.08.2003 event we estimated $\operatorname{Imax}=$ VIII in Lefkada town (Fig. 3). No human victims were reported while about 55 persons were injured. In the remaining part of the island intensity ranged from V to VII. Intensities were assessed in both the 12-point EMS (European Macroseismic Scale) and MM scales and no important differences were found. Slope failures, associated ground fractures and rock falls were observed in several steep slopes consisting mainly of unstable, cracked limestone masses predominantly along the western part of the island. The most impressive landslides, classified as disrupted soils, rock slides and rock falls according to Varnes' (1978) scheme, occurred in $\sim 3 \mathrm{~km}$ length of the Agios Nikitas-Pefkoulia road (Fig. 3, 4). Liquefaction in artificial fill and underlying sand layers was observed in the Marina district, Lefkada town. Surface evidence of liquefaction also comes from ground craters opened in the sandy beach of Agios Nikitas, the largest of them being of diameter $\sim 3.5 \mathrm{~m}$ and depth $\sim 1.5 \mathrm{~m}$ (Fig. 5 ).

Focal parameters and macroseismic features of the 1914, 1948 and 2003 strong shocks along with the respective documentary sources are summarized in Table 1 making clear that three out of four strong instrumental earthquakes shared the north section of the Lefkada fault segment and had nearly stable slip which is interpreted well by the characteristic earthquake model. Then, the severity of the ground motion anticipated at a particular point of observation under constant ground conditions should be roughly the same for the characteristic earthquake. This is evident from the quite similar ground failures caused by each one of the three shocks in the same locations under same ground conditions.

In fact, for a permanent slope failure to be caused it is needed $a_{y} / \alpha_{\max }<1$, that is the maximum horizontal ground acceleration, $\alpha_{\max }$, to exceed the yield acceleration, $a_{y}=k_{y} g$, which is the minimum pseudostatic acceleration required to produce instability of a potential failure mass in a slope, where $k_{y}$ is the yield coefficient and $g$ is the grav- 


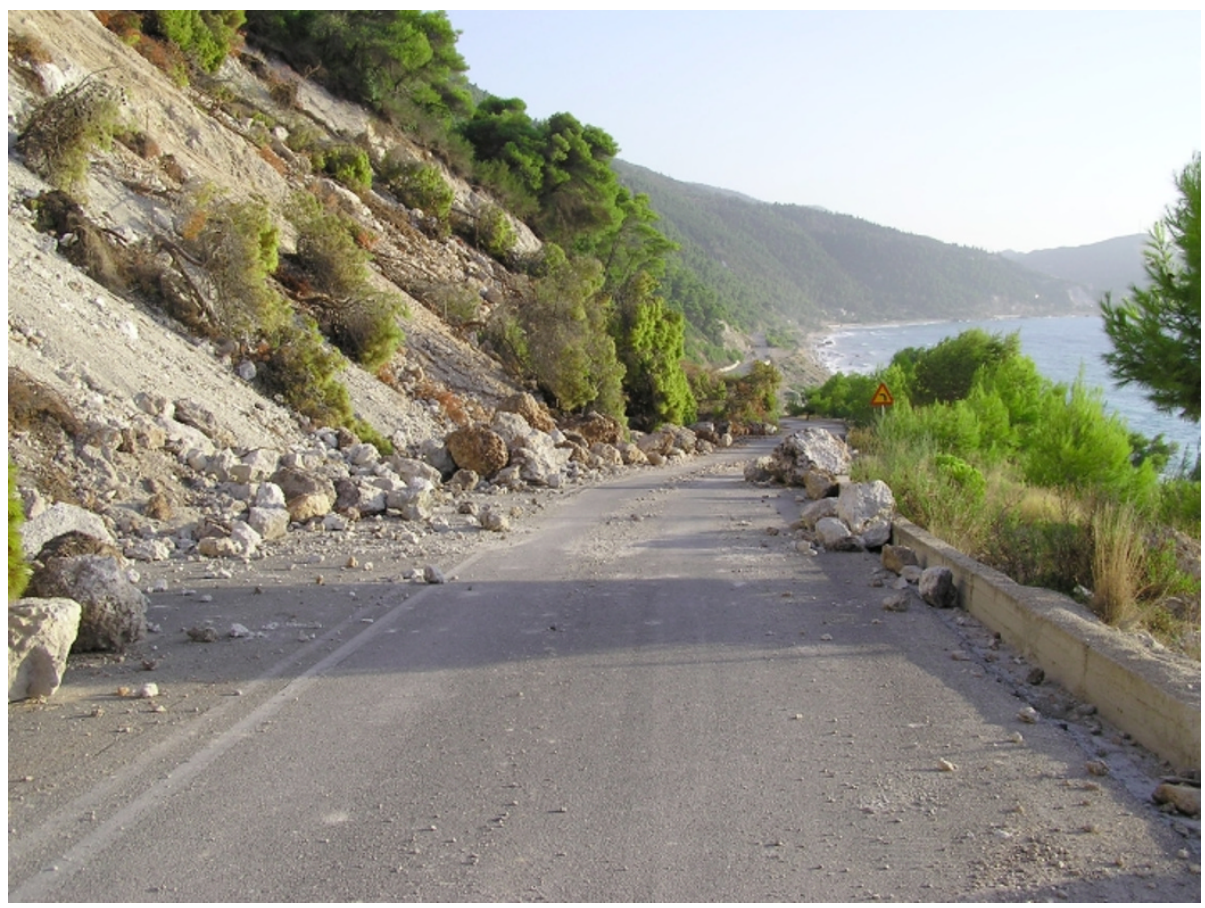

Fig. 4. Landslide in Pefkoulia (see location in Fig. 3).

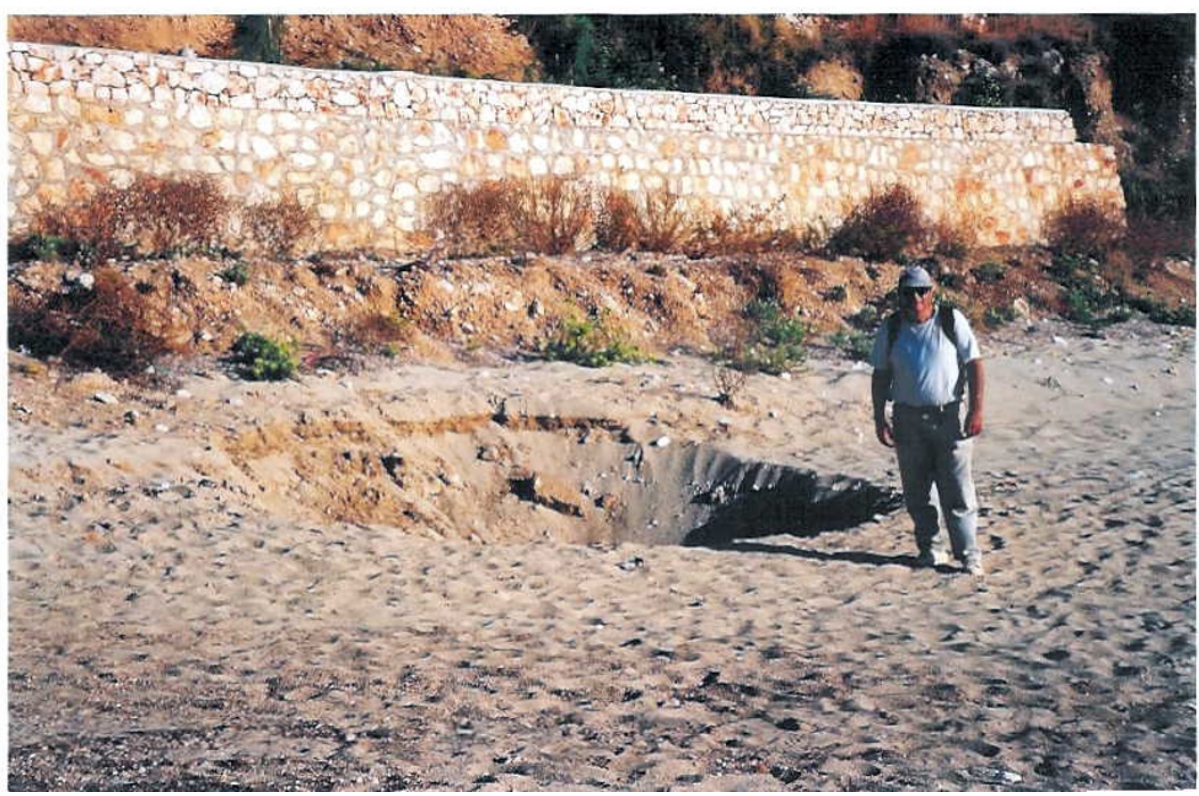

Fig. 5. Ground crater opened in the sandy beach of Agios Nikitas.

ity acceleration; the vertical component of ground acceleration is neglected as it has less influence (e.g. see review in Kramer, 1996). However, in a particular failure plane the yield coefficient is constant since $k_{y}=\tan (\phi-\beta)$, where $\phi=$ Mohr-Coulomb shear strength parameter and $\beta=$ inclination of the failure plane. This means that during the three characteristic earthquakes of 27.11.1914, 30.06.1948 and 14.08.2003, horizontal acceleration in a particular steep slope that slided, like that of Agios NikitasPefkoulia, exceeded a stable value of $a_{y}$, which certainly is less than $\alpha_{\max }=0.41 \mathrm{~g}$, the peak ground acceleration expected from the 2003 shock for Agios Nikitas-Pefkoulia at
$\Delta=12 \mathrm{~km}$ from an attenuation formula for Greek earthquakes (Theodulidis, 1991). In Lefkada town at $\Delta=15 \mathrm{~km}$, $\alpha_{\max }=0.42 \mathrm{~g}$ was recorded during the 2003 earthquake while $\alpha_{\max }=0.39 \mathrm{~g}$ is expected from the attenuation formula.

The densification of dry sand subjected to seismic loading, like that occurred in the ground craters in Agios Nikitas beach, depends on the density of the sand, $\rho$, the amplitude of the cyclic shear strain induced in the sand, and the number of cycles of shear strain applied during the earthquake (Silver and Seed, 1971). Since $\rho$ is constant and the settlement due to densification is on the same order for the three 1914, June 
1948 and 2003 earthquakes, the other two factors should be similar, thus providing additional evidence that the source properties of the three events should have been similar.

\section{Concluding Remarks and Discussion}

The four strong shocks examined have great similarity in size. However, epicentral determinations indicate that while the earthquakes of 27.11.1914, 30.06.1948 and 14.08.2003 ruptured the north section of the LFS, the earthquake of 22.04.1948 ruptured the south section, thus indicating small slip rate in the south section as compared with the north section. Comparable Imax was estimated for the 27.11.1914 and 30.06.1948 events, while it was less in the 14.08.2003 shock very possibly because of building improvement with time due to the establishment of antiseismic codes after the 1948 shocks. The pattern of intensity distribution, however, was again the same in the three shocks with most affected being the north-northwest part of Lefkada. On the contrary, the 22.04.1948 shock affected the south-southwest part of Lefkada and north Ithaki island, which is consistent with the instrumental location of the epicenter. This implies that the 1948 rupture process started with the 22.04.1948 shock from the south LFS which seems to have resisted the 2003 rupture. Then, the rupture migrated with the 30.06 .1948 shock to the north section which coincides with the 27.11.1914 and 14.08.2003 rupture zones. It should be noticed that all four strong shocks did not cause intensity exceeding degree VI in the Greek mainland to the east of Lefkada island.

The occurrence of three strong shocks on the north LFS during about the last 100 years implies strain rates of the order of $6 \times 10^{-5} / \mathrm{yr}$ which is not only two orders of magnitude greater than the rate of $1.8 \times 10^{-7} / \mathrm{yr}$ measured by GPS (Kahle et al., 1995), but also more than one order of magnitude greater than strain rates calculated for other highly seismogenic strike-slip faults like the North Anatolian and San Andreas ones. This discrepancy makes a serious problem which certainly deserves to be examined in depth.

In summary, instrumental and field evidence both indicate that the Lefkada fault segment very possibly produces characteristic earthquakes with magnitudes dominating the range from $M s=6.3$ to $M s=6.5$. This result is of significant implications for understanding better the seismotectonics and assessing seismic hazard in the region.

Acknowledgments. This paper has been written within the frame of the research project LEWIS (Landslide Early Warning and Information System), supported by the Commission of European Communities-DG XII, contr. n. EVG1-CT-2001-00055, and partly by the General Secretary of Research and Technology, Greece. Thanks are extended to the Lefkada Prefecture for supporting the stay of G.A.P., V.K. and A.F. during the post-event field survey in Lefkada. Thanks are due to two anonymous reviewers who made useful comments for the improvement of the initial version of the paper.

\section{References}

Critikos, N., L'île de Leucade et des sismes du 23 et du 27 Novembre 1914, Annales de l'Observatoire National d'Athènes, VII, Athènes, 62-81, 1916.

Eginitis, D., Les tremblements de terre de Leucade et d' Ithaque des 23 et 27 Novembre 1914 et du 27 Janvier 1915, Annales de l'Observatoire
National d' Athènes, VII, Athènes, 27-32, 1916.

Galanopoulos, A. G., Die Seismizität der Insel Leukas, Gerl. Beitr. Geophys., 63, 1-15, 1950.

Grant, L. B., Uncharacteristic earthquakes on the San Andreas Fault, Science, 272, 826-827, 1996

HRV, Harvard CMT Solutions, http:/www.seismology.harvard.edu/ CMTsearch.html, last access 10 September 2003, http://www.gein.noa gr, Earthquake Catalogues.

Kagan, Y. Y., Statistics of characteristic earthquakes, Bull. Seism. Soc. Am., 83, 7-24, 1993.

Kahle, H.-G., The Kephalonia transform fault and the rotation of the Apulian platform: evidence from satellite geodesy, Geophys. Res. Lett., 20, 651-654, 1993.

Kahle, H.-G., M. V. Müller, A. Geiger, G. Danuser, S. Mueller, G. Veis, H. Billiris, and D. Pradissis, The strain field in northwestern Greece and the Ionian Islands: results inferred from GPS measurements, Tectonophysics, 249, 41-52, 1995

Kramer, S. L., Geotechnical Earthquake Engineering, pp. 653, Prentice Hall Edit., Washington, 1996.

Louvari, E., A. A. Kiratzi, and B. C. Papazachos, The Cephalonia Transform Fault and its extension to western Lefkada Island (Greece), Tectonophysics, 308, 223-236, 1999

NOAGI, National Observatory of Athens, Institute of Geodynamics, http://www.gein.noa.gr, Earthquake Catalogues, 2003.

Papadopoulos, G. A., H. G. Skafida, and I. T. Vassiliou. Nonlinearity of the magnitude-frequency relation in the Hellenic Arc-Trench System and the characteristic earthquake model, J. Geophys. Res., 98, 17,73717,744, 1993.

Papadopoulos, G. A., K. Konstantinou, and A. Fokaefs, Empirical relationships between magnitude and aftershock area dimensions for Mediterranean region earthquakes, 2003 (submitted).

Papazachos, B. and P. Comninakis, Geophysical and tectonic features of the Aegean arc, J. Geophys. Res., 76, 8517-8533, 1971.

Papazachos, B. C. and C. B. Papazachou, The Earthquakes of Greece, pp. 304, Ziti Edit., Thessaloniki, 1997.

Pavlides, S., G. Papathanasiou, A. Ganas, G. A. Papadopoulos, V. Karastathis, and D. Keramydas, The 14 August 2003 Lefkada (Ionian Sea) Earthquake: field observations, 1st International Workshop on Earthquake Prediction, Europ. Seism. Commission, Athens, 6-7 November 2003, edited by G. A. Papadopoulos, 2 : Extended Abstracts, 2003.

Roberts, G. P., Noncharacteristic normal faulting surface ruptures from the Gulf of Corinth, Greece, J. Geophys. Res., 101, 25,255-25,267, 1996.

Schwartz, D. P. and K. J. Coppersmith, Fault behavior and characteristic earthquakes: Examples from the Wasatch and San Andreas Fault Zones, J. Geophys. Res., 89, 5681-5698, 1984.

Schwartz, D. P., K. J. Coppersmith, F. H. Swan, P. Somerville, and W. U. Savage, Characteristic earthquakes on intraplate normal faults, Earthquake Notes, 52, 71, 1981.

Silver, N. L. and H. B. Seed, Volume changes in sands during cyclic loading, J. Soil Mech. Found. Div., ASCE, 97, 1171, 1971.

Thatcher, W., Order and diversity in the modes of circum-Pacific earthquake recurrence, J. Geophys. Res., 95, 2609-2623, 1990.

Theodulidis, N. P., Contribution to the study of strong motion in Greece, Ph.D. Thesis, Univ. Thessaloniki, pp. 500, 1991 (in Greek).

USGS, United States Geological Survey, National Earthquake Information Center, http://gldss7.cr.usgs.gov/neis/bulletin/bulletin.html, last access 10 September 2003.

Valle, P., Il terremoto Jonico del 22 Aprile 1948, Annali di Geofisica, 4, 241-245, 1951.

Varnes, D. J., Slope movement types and processes, Landslides: Analysis and Control, Transportation Research Board Special Report 176, National Academy of Sciences, Washington, D.C., 12-33, 1978.

Wells, D. L. and K. J. Coppersmith, New empirical relationships among magnitude, rupture length, rupture width, rupture area, and surface displacement, Bull. Seism. Soc. Am., 84, 974-1002, 1994.

Wesnousky, S. G., C. H. Scholz, K. Shimazaki, and T. Matsuda, Earthquake frequency and the mechanics of faulting, J. Geophys. Res., 88, 93319340, 1983.

G. A. Papadopoulos (e-mail: g.papad@gein.noa.gr), V. K. Karastathis, A. Ganas, S. Pavlides, A. Fokaefs, and K. Orfanogiannaki 